\title{
REGIONAL CHEMOTHERAPY OF NEOPLASTIC DISEASES
}

\author{
William D. EnSminger and JoHN W. Gyves \\ Cancer Pharmacology Program, University of Michigan Medical School, UpJohn Center For Clinical \\ Pharmacology, Ann Arbor, Michigan 48109, U.S.A.
}

\section{PERSPECTIVE ON REGIONAL CANCER CHEMOTHERAPY}

A number of common tumors have a propensity for confinement to specific body regions or organs. In a significant number of patients it is the regional tumor, and not widespread metastases, which causes morbidity and eventually death. In a few circumstances, surgical resection of isolated metastases can be curative. For example, resection of a single, isolated hepatic nodule can lead to a cure in up to $25 \%$ of cases (Latham and Foster, 1967). Unfortunately, even regionally confined metastases are seldom single and are often surgically unresectable due to anatomical location. When all metastatic tumors can be encompassed in a radiation port with sufficient sparing of vital tissues, high dose radiotherapy can sterilize such disease. However, normal tissue tolerance to radiotherapy often impedes the delivery of curative dosages. Regional chemotherapy represents a third potent approach useful in regionally confined cancers.

Even in circumstances where systemically administered (intravenous) chemotherapy is relatively ineffective, regional chemotherapy may still improve the likelihood of response by the generation of much greater drug exposures (higher levels, longer times). Regional chemotherapy administration represents a means to generate increased drug exposure in the region where the tumor resides while maintaining a lower drug exposure at the level of dose-limiting normal host tissues elsewhere in the body. Ideally, the higher level of drug generated regionally will be cytotoxic to the regionally confined tumor while the lower systemic drug level will be below the toxic threshold for the usual dose-limiting tissues such as the bone marrow and gastrointestinal mucosa. With sufficient regional selectivity, dose-limiting toxicity should be manifested by the normal tissues of the region infused and not by tissues elsewhere in the body. In this regard, regional chemotherapy has similarities to radiation therapy but may be more selective when tumor and normal tissue in the treated region differ greatly in intrinsic drug sensitivity (based upon biochemical differences).

As will be described below, regional drug exposures may be increased 100 - to 1000 -fold per given amount of systemic exposure. Such selective improvements are due to the pharmacokinetics of individual agents and to restricted egress from regional compartments or to circumscribed, relatively low regional blood flows. Despite improved regional drug exposure, antineoplastic effect may not be improved if a tumor is either too sensitive or too refractory. If a tumor is extremely sensitive to a given drug, systemic administration may suffice to achieve maximum therapeutic effect. If a tumor is totally refractory to all concentrations of a drug, then the increased exposure generated through regional chemotherapy will be of no benefit.

Regional chemotherapy can be divided into two major categories: administration into a third space regional compartment (cerebrospinal fluid (CSF) space, peritoneal cavity, pleural space, pericardial space) and, intraarterial infusion into the afferent artery feeding 
the tumor-containing organ or body region. The principles involved are broadly applicable within each category and, therefore, only the most frequent and significant regional chemotherapies will be discussed below.

Interest in regional chemotherapy has been stimulated by two recent developments in clinical pharmacology. The first is the ability to measure drug levels readily in body fluids. Although a number of techniques have been utilized, high performance liquid chromatographic assays have been developed for most antineoplastic agents of interest. Hence, the basic pharmacokinetic properties relevant to a drug's potential usefulness in regional chemotherapy often are determined early in clinical protocols. When a given drug has the appropriate properties, the improved regionally selective drug levels can be directly measured in clinical practice. The dependence of selectivity on route of administration, dose rate, schedule, infusion volumes, etc. can be ascertained comparing regional drug levels with systemic drug levels (Ensminger et al., 1978a).

The second impetus to regional chemotherapy has been the development of improved devices for the controlled delivery of drug solutions into appropriate blood vessels or body spaces. Extracorporeal volumetric infusion pumps have improved accuracy and reliability. With refinement in drug therapy and more potent drugs, such external infusion pumps have proliferated in numbers within the hospital setting. Portable external pumps have come into use and are being refined. However, the development of a totally implanted pump (Blackshear et al., 1970; Buchwald et al., 1980; Ensminger et al., 1981a) has made it possible to give protracted infusions safely and reliably to outpatients with relatively few restrictions on the patient's lifestyle. The only commercially available pump, the Model 400 Infusaid Pump (Fig. 1) has been implanted in over 2,000 patients (B. Enegren, Sales Manager, Infusaid Corp., Sharon, Ma., personal communication). Although the majority

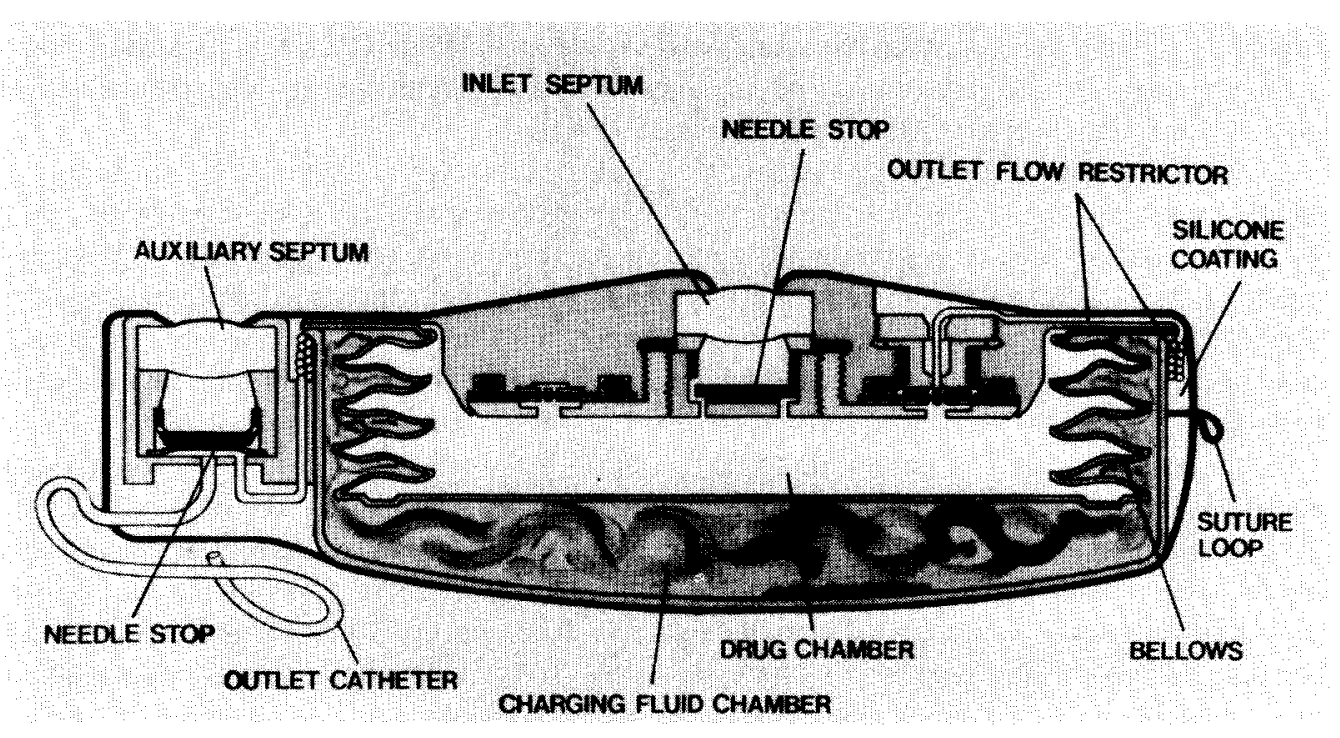

Fig. 1. Diagram of the Model 400 Infusaid pump produced by Infusaid Corporation, Sharon, MA. The Model 400 pump has a side port with an auxiliary septum which bypass the pumping mechanism for direct catheter injection. The disc-shaped pump is separated into two chambers by titanium bellows. The inner drug chamber contains the solution to be infused. The outer chamber contains a fluorocarbon liquid in equilibrium with its vapor phase. At $37^{\circ} \mathrm{C}$, the vapor pressure exerted by this substance is approximately $300 \mathrm{mmHg}$ greater than atmospheric pressure. This vapor pressure provides the power source, exerting pressure on the bellows and forcing infusate through a $0.22 \mu \mathrm{m}$ bacterial filter and a flow-regulating resistance element. The pump is placed beneath the skin, and the inner drug chamber is refilled by percutaneous injection though a self-sealing septum. The pressure of this injection compresses the fluorocarbon vapor back to the liquid phase, thus simultaneously filling the pump and recharging the power source. The pump has a $50 \mathrm{ml}$ capacity and flow rates of individual pumps are factory calibrated to deliver a constant set rate, usually, in the range of $2-3 \mathrm{ml} /$ day. Diagram courtesy of Infusaid Corporation. The UNFUSAID $^{\text {TM }}$ pump is the only commercially available implantable pump and has been implanted in over 2000 patients. 
of pumps being impanted are for hepatic arterial chemotherapy, some are being used for intrathecal morphine infusions for pain control (Greenberg et al., 1982), for intraventricular and intraarterial treatment of central nervous system tumors (Dakhil et al., 1981a; Phillips et al., 1982), for intravenous infusions of heparin in thrombotic disorders (Rohde et al., 1977), and for intravenous infusions of insulin in Type II diabetes (Buchwald et al., 1981). Externally programmable, yet totally implantable, infusion pumps produced by a number of manufacturers are in early clinical trails (Schade et al., 1982). Implantable pumps are not suitable for drugs requiring administration in large fluid volumes, for drugs that are unstable, and for drugs best administered in boluses or short infusions. However, even for such drugs and in circumstances where reliable repeated access is required, small implanted injection ports attached to silastic catheters can provide a safe and convenient means of access (Gyves et al., 1982a).

\section{THIRD SPACE CHEMOTHERAPY}

There are a number of circumstances where tumors are largely confined to body cavities (or third spaces) without significant invasion into lining tissues. Examples are meningeal carcinomatosis in the cerebrospinal fluid (CSF) space and malignant ascites within the peritoneal cavity. Direct drug instillation into the CSF space has been frequently practiced for control of meningeal tumor using methotrexate (MTX) most commonly (Shapiro et al., 1975; Bleyer and Poplack, 1978). In the past few years, direct drug administration into the peritoneal cavity has also been extensively investigated (Dedrick et al., 1978; Speyer et al., 1980). The pharmacological principles applicable to these two spaces have similarities and can be generalized to other body spaces such as the pleural and pericardial cavities (Howell et al., 1981).

\subsection{Third Space Pharmacokinetic Principles}

The pharmacokinetic properties of a given drug determine whether direct administration into a given body space will be advantageous in terms of generating increased drug exposure in the fluid (and on the surfaces lining that space) relative to systemic exposure. The pharmacokinetic modeling appropriate to antineoplastic drugs for third space administration has been defined (Dedrick et al., 1978; Howell et al., 1981). A drug within the body cavity crosses the lining membrane of area $(A)$ by a diffusive process characterized by a permeability $(P)$. As commonly practiced, the intrinsic $P$ is not measured separately, but only in combination with the associated A to generate a permeability-area product $(P A)$.

\subsubsection{CSF Space}

Using a simplified two compartment model (Bleyer and Dedrick, 1977), the mass balance equation is

$$
-V_{\mathrm{CNS}} \frac{\mathrm{d} C_{\mathrm{CSF}}}{\mathrm{d} t}=r+P A\left(C_{\mathrm{CSF}}-C_{\mathrm{p}}\right)+Q_{\mathrm{CSF}} \cdot C_{\mathrm{CSF}}
$$

where $V_{\mathrm{CNS}}$ equals the volume of CSF plus the extracellular fluid volume of the brain and spinal cord, $C_{\mathrm{CSF}}$ the CSF drug concentration and $C_{\mathrm{p}}$ the plasma drug concentration, $Q_{\mathrm{CSF}}$ the rate of bulk flow of CSF from the CSF space by arachnoid villi uptake and, $r$ the active transport component ( $r$ is felt to be 0 for MTX). For MTX, $P A$ is approximately $1 \mathrm{ml} / \mathrm{hr}$ with a CSF bulk flow $\left(Q_{\mathrm{CSF}}\right)$ of approximately $30 \mathrm{ml} / \mathrm{hr}$ or $0.5 \mathrm{ml} / \mathrm{min}$ (Bleyer and Dedrick, 1977). Hence, bulk flow dominates removal of MTX from the CSF space. Since MTX is not metabolized in the CSF space, steady state infusion into the CSF space at rate $I$ leads to steady-state infusion into the vascular compartment (or systemic circulation) at rate $I$. The resultant systemic plasma level $\left(C_{\mathrm{p}}\right)$ is related to the infusion rate and total body clearance $\left(C L_{\mathrm{TB}}\right)$ as follows:

$$
C_{\mathrm{p}}=I / C L_{\mathrm{TB}}
$$


If the steady state dose rate of MTX infusion into CSF space is much larger than the quantity of drug transported from plasma back to CSF space, then

$$
C_{\mathrm{CSF}} \cong I / Q_{\mathrm{CSF}}
$$

and,

$$
C_{\mathrm{CSF}} / C_{\mathrm{p}} \cong C L_{\mathrm{TB}} / Q_{\mathrm{CSF}}
$$

For MTX which is excreted primarily by the kidneys, $C L_{\mathrm{TB}}$ equals or exceeds creatinine clearance and thus is usually at least $100 \mathrm{ml} / \mathrm{min}$. Hence, with direct CSF space infusion of MTX,

$$
\text { Selective advantage }=C_{\mathrm{CSF}} / C_{\mathrm{p}} \cong \frac{100 \mathrm{ml} / \mathrm{min}}{0.5 \mathrm{ml} / \mathrm{min}} \cong 200
$$

A totally implanted system for direct constant intraventricular infusions has been developed in monkeys and utilized in patients with central nervous system (CNS) tumors (Dakhil et al., 1981a). Using this system in patients, the selective advantage at steady-state for direct intraventricular infusion of MTX exceeds 200, which is as predicted above. Assuming that the bulk flow rate, $Q_{\mathrm{CSF}}$, is relatively constant at approximately $0.5 \mathrm{ml} / \mathrm{min}$, then $C L_{\mathrm{TB}}$ becomes the crucial factor in determining the selective regional advantage of any given drug. It will be seen later that a drug's total body clearance is a crucial selective factor also with infusions into other body cavities as well as with regional intraarterial infusions.

Fluorodeoxyuridine (FUDR) and cytosine arabinoside (AraC) are two pyrimidine antimetabolites which have even higher $C L_{\mathrm{TB}}$ than MTX. Constant intraventricular infusion of FUDR, in particular, generates at least a 1000-fold higher steady-state CSF space level than plasma level (Dakhil et al., 1981b). The $P A$ 's for FUDR and AraC have not been determined, but are probably greater than that for MTX based on their CSF pharmacokinetics in comparison with ytterbium-169 labeled diethyltriamine pentacetic acid (DTPA), an agent which is removed from the CSF space solely by bulk flow.

Although a system for constant CSF space drug infusion has been recently developed, the vast majority of prior investigational and clinical usages have concerned bolus drug injections into the CSF space (Bleyer and Poplack, 1978). The development of ventriculostomy reservoirs has greatly facilitated repeated access to the entire CSF space. Injection of a drug solution into a lateral ventricle leads to distribution throughout the CSF space as most CSF is produced by the ventricular choroid plexus, whereas, injection of drug into the lumbar sac does not always lead to adequate retrograde drug flow into the ventricles (Rieselbach et al., 1962; Shapiro et al., 1975). With bolus intraventricular injection of MTX, CSF drug levels are generated which are several hundred-fold concurrent systemic levels (Shapiro et al., 1975). MTX levels are not uniform throughout the CSF space at any given time-point due to bulk flow of CSF from the site of injection with continued CSF production. Systemic plasma levels rise and peak over 4-8 hr with the arrival of the wave of MTX-containing CSF at the arachnoid villi. Both CSF and plasma levels fall in a relatively parallel fashion with time thereafter. The systemic plasma levels achieved with bolus intraventricular injection may exceed the toxic threshold for a long enough time to generate systemic toxicity with MTX. Frequent intraventricular injection of much smaller MTX doses has been proposed as a mechanism to sustain therapeutic CSF space drug levels without the generation of toxic systemic levels (Bleyer et al., 1978). As depicted in Fig. 2, constant intraventricular infusion offers the best method for precise maintenance of a high CSF level with a lower systemic level. Other factors such as cost and risks of an implanted system as well as duration of need for therapy will play an important role in determining whether to implant a pump for constant infusion or to simulate a constant infusion with multiple daily injections. With antimetabolites such as MTX, AraC and FUDR, cytotoxicity is related to duration of exposure above a threshold concentration with the toxic threshold and duration variable from tissue to tissue (Pinedo and Chabner, 


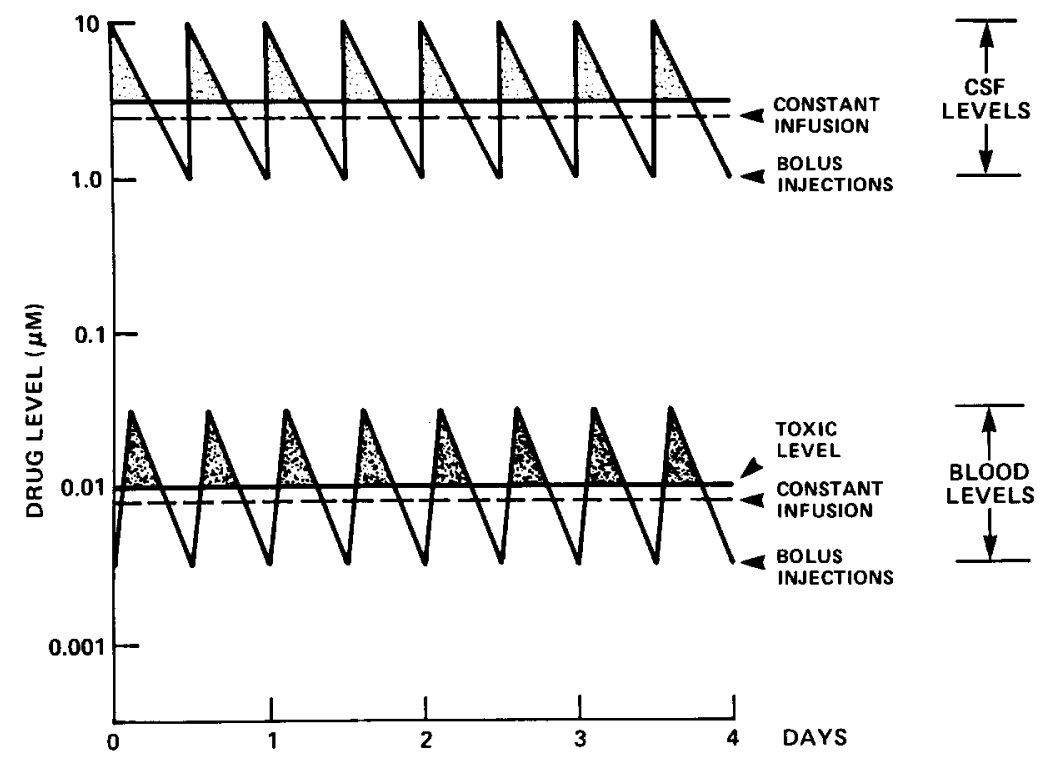

FIG. 2. Simplified graphic representation of resultant CSF and plasma drug levels after twice daily intraventricular bolus versus constant intraventricular infusion of a chemotherapeutic agent such as methotrexate. A controlled constant infusion at the correct level should not generate toxic peak levels or less than therapeutically optimal trough levels.

1977). These antimetabolities are cell-cycle and phase-specific which means that nonproliferating cells such as normal brain and stromal tissues are less sensitive than proliferating tumor cells. The longer the drug exposure is maintained above the toxic threshold for the tumor cells in the CSF space, the greater the proportion of tumor cells which will be destroyed.

The only other antineoplastic agent used intrathecally has been the alkylating agent, thio-tepa (Gutin et al., 1976). Thio-tepa is more lipid soluble than the aformentioned antimetabolies and therefore is likely to be more readily absorbed (i.e. have a larger PA) from the CSF space than MTX, AraC and FUDR. It is noteworthy that alkylating agents affect cytotoxicity more in relation to their peak level than duration of exposure. Hence, bolus administration of intraventricular thio-tepa would seem to be the most rational schedule.

\subsubsection{Intraperitoneal and other Third Spaces}

The pharmacokinetic rationale for the intraperitoneal administration of antineoplastic agents has been delineated by Dedrick and associates at the National Cancer Institute (Dedrick et al., 1978) and generalized to pleural and pericardial administration of MTX by Howell and associates (Howell et al., 1981). At steady state, the selective advantage of a direct drug infusion into a third space in terms of third space level $\left(C_{\mathrm{TS}}\right)$ to systemic plasma level $\left(C_{\mathrm{p}}\right)$ relates as follows to the total body drug clearance $\left(C L_{\mathrm{TB}}\right)$ and the permeability-area product $(P A)$

$$
\text { Selective advantage }=\frac{C_{\mathrm{TS}}}{C_{\mathrm{p}}}=\frac{R(P A)+C L_{\mathrm{TB}}}{P A}
$$

where $R$ represents the effusion to plasma MTX concentration partition ratio determined by equilibrium dialysis (required to account for plasma protein binding). When $R$ equals 1 as it is for MTX, then:

$$
\text { Selective advantage }=\frac{C_{\mathrm{TS}}}{C_{\mathrm{p}}}=1+\left(\frac{C L_{\mathrm{TB}}}{P A}\right)
$$


TABLE 1. Selectivity of Direct Drug Infusions Into Third Spaces

\begin{tabular}{lccccl}
\hline & \multicolumn{4}{c}{ Concurrent Drug Levels $(\mu \mathrm{M})$} & \\
\cline { 3 - 5 } Space & Drug & Third Space $\left(C_{\mathrm{TS}}\right)$ & Plasma $\left(C_{\mathrm{p}}\right)$ & $C_{\mathrm{TS}} / C_{\mathrm{p}}$ & Reference \\
\hline CSF & MTX & $2-30$ & $<0.01$ & $200-300$ & Dakhil et al., 1981a \\
CSF & FUDR & $4-14$ & $<0.01$ & $200-14,000$ & Dakhil et al., 1981b \\
Peritoneal & FU & $100-200$ & $0.10-0.46$ & $200-2,000$ & Gyves et al., 1982e \\
Peritoneal & MTX & 24 & 0.7 & 30 & Howell et al., 1981 \\
Pleural & MTX & 213 & 1.0 & 200 & Howell et al., 1981 \\
Pericardial & MTX & 434 & 1.2 & 300 & Howell et al., 1981 \\
\hline
\end{tabular}

Table 1 summarizes the data obtained by several investigators pertaining to intraperitoneal MTX and fluorouracil (FU) infusions as well as to intrapleural and intrapericardial MTX infusions. Thus it can be seen that for both MTX and FU, direct infusion into a third space generates at least 100 -fold selective third space drug exposure and that this exposure is a function of $C L_{\mathrm{TB}}$ and the $P A$ for the drug. If $C L_{\mathrm{TB}}$ falls, the selective advantage may fall with constant $P A$. Hence the importance of sustaining a high $C L_{\mathrm{TB}}$ through maintainance of adequate hepatic and renal function. If the membrane area for diffusion decreases, then $P A$ will fall, and, for constant $C L_{\mathrm{TB}}$, the selective advantage for the space defined by the membrane in question will rise.

Intracavitary chemotherapy is limited in applicability to free-floating tumor cells and to tumors of small thickness on the lining of the cavity. Grossly visible tumors are likely to receive their blood supply from the systemic circulation with limited drug diffusion from the surface facing the cavity. Furthermore, there is difficulty quantitating response under circumstances where tumor is solely microscopic. The loss of malignant cytology in an effusion has been used by some to denote a response. Such a response can be meaningful only when there are no gross tumors and when the entire surface lining the cavity is being bathed by the drug-containing solution (i.e. there should be no loculated sanctuaries with limited access to the drug solution).

Interest has been stimulated in the use of intraperitoneal chemotherapy for the treatment of ovarian cancer, particularly in an adjuvant setting (Dedrick et al., 1978). Ovarian cancer spreads intraabdominally within peritoneal fluid. Single cells implant on the peritoneal surface, exfoliate and migrate intraperitoneally via the ascitic fluid to new sites. Application of intraperitoneal therapy can expose individual floating tumor cells and microscopic surface implants to much higher drug levels than achievable with systemic infusion. Such high drug levels may directly kill tumor cells, but, in addition, may change the peritoneal surface so that implantation becomes less likely (a poor soil hypothesis). The results of these efforts to date are preliminary but suggest that intraperitoneal chemotherapy may be effective in adjuvant therapy for early stages of ovarian cancer (Ozols et al., 1982).

About $70 \%$ of intraperitoneal FU exists via the portal vein (Speyer et al., 1981). With intraperitoneal FU administration, portal vein drug levels are about 4-fold higher than those generated by intravenous administration of FU at the same dose rate. In addition, it is likely that the lymphatic drainage from the peritoneal cavity contains high drug concentrations with intraperitoneal FU administration. As further discussed below, increased intraperitoneal drug exposure and portal vein $\mathrm{FU}$ levels with intraperitoneal FU administration may be advantageous in the adjuvant treatment of high risk colon cancer.

For hepatic tumors it is likely that the original microscopic (metastatic) tumor cell deposits derive much of their blood supply from the portal vein (Ackerman et al., 1969). Hence, for adjuvant treatment of microscopic liver metastases, portal vein infusions or intraperitoneal drug infusions may be rational. However, with the neovascularization accompanying tumor growth, the portal supply is obliterated and the arterial supply becomes predominant for grossly detectable disease (Breedis and Young, 1954).

Without adjuvant treatment, primary resection of colon cancer which has penetrated through the bowel wall to the serosa and adjacent lymph nodes (Dukes C) leads to cure in only $25 \%$ of patients. In one British study, constant infusion of $1 \mathrm{~g} /$ day of $\mathrm{FU}$ into the 
portal vein for seven days post-operatively after primary resection of Dukes $\mathrm{C}$ lesions led to a reduction in relapse rate at two years from 68 to $17 \%$ (Taylor et al., 1979). Direct intraperitoneal FU administration potentially could achieve the same end as a portal vein infusion. Direct portal vein infusion of $F U$ (assuming a portal vein blood flow of $0.5 \mathrm{l} / \mathrm{min}$ and a $C L_{\mathrm{TB}}$ of $\mathrm{FU}$ of $5 \mathrm{l} / \mathrm{min}$ - see discussion below) should generate a 10 -fold increased hepatic exposure as compared to the 4-fold increase in portal vein FU level anticipated with intraperitoneal administration.

The contribution of starting the seven day FU infusion immediately post-operatively in the prevention of tumor implantation and growth throughout the body versus the contribution of higher portal FU levels in killing microscopic intrahepatic implants needs to be ascertained. The physiological milieu immediately post-operative may favor implantation of tumor cells and perhaps even a systemic FU infusion would inhibit such implantation if given immediately after operation. It is an accepted principle/phenomenon in adjuvant chemotherapy that treatment results are markedly affected by delay in giving drug post-operatively. Recently introduced drug delivery devices (external and implantable pumps, injection ports) may make randomized trials of portal vein, intraperitoneal, and systemic adjuvant treatment with constant infusion FU and other drugs more feasible.

\section{INTRAARTERIAL CHEMOTHERAPY}

Intraarterial chemotherapy has been most extensively applied to the treatment of primary and metastatic cancer in the liver. However, other body regions and tumor types studied in the past and currently under investigation include external carotid arterial infusions for head and neck cancers, internal carotid and vertebral arterial infusions for primary and metastatic brain tumors, femoral and brachial arterial infusions for melanomas and sarcomas of the extremities, and infusion of various pelvic arteries for urogenital tumors.

There are a number of often neglected crucial elements in successful intraarterial chemotherapy: 1. Use of a drug which has appropriate pharmacokinetics, dose-response and schedule dependency; 2 . Catheter placement so as to infuse the entire tumor-bearing region; 3. Use of a delivery system which allows repeated and chronic administration conveniently and reliably, preferably in an outpatient setting.

\subsection{Pharmacokinetics}

The theoretical pharmacokinetic basis defining the advantages of intraarterial drug infusions has been described by Eckman and associates (Eckman et al., 1974) and by Chen and Gross (Chen and Gross, 1980). In order to quantitate the delivery advantage to the site in question, the ratio of regional exposure after regional arterial infusion is compared to that after venous infusion at the same dose rate. The advantage of increased drug delivery resulting from arterial infusion is determined by factors which influence the time integrals of the arterial drug levels obtained by arterial vs venous infusion, respectively. Using a physiologically based pharmacokinetic model, Chen and Gross (Chen and Gross, $1980)$ demonstrated that the regional drug exposure advantage $\left(R_{\mathrm{d}}\right)$ for agents with linear pharmacokinetics is related to the rate of drug elimination in the rest of the body and the blood perfusion rate into the target region by the formula

$$
\text { Advantage }\left(R_{\mathrm{d}}\right)=1+C L_{\text {app }} / Q_{\mathrm{t}}
$$

where $C L_{\text {app }}$ is the total body drug clearance from the rest of the body excluding the tumor (target) region and $Q_{\mathrm{T}}$ is the blood flow through the regional artery being infused. Intraarterial infusion will reduce drug delivery and availability to the rest of the body by

$$
R_{\mathrm{d}}=1-E_{\mathrm{T}}
$$

where $E_{\mathrm{T}}$ is the extraction ratio of the drug by the target region. Combining the advantage 
TABLE 2. Drugs For Intraarterial Infusion

\begin{tabular}{|c|c|c|c|c|c|}
\hline Drug & $\begin{array}{c}T_{1 / 2} \\
(\mathrm{~min})\end{array}$ & $\begin{array}{c}C 1_{\mathrm{TB}} \\
(1 / \mathrm{min})\end{array}$ & $E_{\mathrm{H}}$ & $\begin{array}{c}\text { Estimated } \\
\text { Increased Exposure } \\
\text { With Hepatic } \\
\text { Arterial Infusion }\end{array}$ & Reference \\
\hline FU & 10 & 5 & 0.80 & 100 & Ensminger et al., 1983 \\
\hline FUDR & $<10$ & $5-15$ & $0.69-0.92$ & 400 & Ensminger et al., 1978a \\
\hline $\mathrm{BCNU}$ & $<5$ & 2.5 & & 12 & Ensminger et al., $1978 \mathrm{~b}$ \\
\hline Mitomycin C & $\leq 10$ & 0.6 & $0.07-0.18$ & $3-4$ & Gyves et al., 1983 \\
\hline Cisplatin & $20-30$ & & & $4-7$ & Kelson et al., 1980 \\
\hline Dichloromethotrexate & & & $0.40-0.70$ & 6 & Ensminger et al., $1981 \mathrm{~b}$ \\
\hline
\end{tabular}

gained through the total body clearance relative to regional blood flow plus that gained by regional extraction

$$
\text { Regional Advantage }=1+\frac{C L_{\mathrm{TB}}}{Q_{\mathrm{T}}\left(1-E_{\mathrm{T}}\right)}=\left(\frac{0.693 V_{\mathrm{d}}}{t_{1 / 2}}\right) / Q_{\mathrm{T}}\left(1-E_{\mathrm{T}}\right)
$$

where $C L_{\mathrm{TB}}$ is total body drug clearance, $V_{\mathrm{d}}$ is the volume of distribution, $t_{1 / 2}$ the elimination half-life and $Q_{\mathrm{T}}$ and $E_{\mathrm{T}}$ are as noted above. Hence, in analogy with third space drug infusions (Eqns 6 and 7), regional selectivity is a direct function of a drug's total body clearance. Thus, agents with high total body clearance are essential for maximum effect for both third space as well as intraarterial chemotherapy.

Table 2 presents the pertinent pharmacokinetic parameters and estimates of the improved regional hepatic exposure with hepatic arterial drug infusion, the most common form of intraarterial infusion practiced. Most of the drugs used in hepatic arterial chemotherapy have short plasma half-lives and high total body clearances. The two most commonly utilized used drugs, 5-fluorouracil (FU) and 5-fluoro-2'-deoxyuridine (FUDR), have half-lives of $10 \mathrm{~min}$ or less with high total body clearances plus extensive hepatic extraction. Calculations based on direct blood level determinations indicate as much as a 100-fold advantage for FU (Ensminger et al., 1983) and a 400-fold advantage for FUDR (Ensminger et al., 1978a) of hepatic arterial over intravenous infusion in the generation of an improved hepatic drug exposure. Although the data is limited, significantly (i.e. $>2$-fold) increased exposure with hepatic arterial infusion is seen for a number of other agents including dichloromethotrexate (Ensminger et al., 1981b), thymidine (Ensminger and Frei, 1978), bischlorethylnitrosourea (Ensminger et al., 1978b), mitomycin C (Tseng et al., 1981), and cis-platinum (Kelsen et al., 1980).

The theoretical principles described above assume that the rate coefficients of drug loss remain constant over the complete range of drug concentrations and throughout the time periods involved. Data obtained with increasing dose rates of thymidine given into the hepatic artery demonstrate that extraction processes can become increasingly saturated with the hepatic extraction dropping from $80 \%$ at $4 \mathrm{~g} / \mathrm{m}^{2}$ per day to less than $20 \%$ at $128 \mathrm{~g} / \mathrm{m}^{2}$ per day (Ensminger and Frei, 1978). Non-linear pharmacokinetics with saturable elimination also apparently hold for infusions of the radiosensitizer 5-bromo-2'-deoxyuridine (Sonneveld et al., 1982). Recent investigation (Ensminger et al., 1983) has confirmed the non-linear pharmacokinetics of FU first described by Collins and associates (Collins et al., 1980). At dose rates of $20 \mathrm{mg} / \mathrm{kg}$ per day as a constant infusion, the $C L_{\mathrm{TB}}$ of $\mathrm{FU}$ is approximately $5 \mathrm{1} / \mathrm{min}$, falling to less than $1 \mathrm{l} / \mathrm{min}$ at dose rates exceeding $270 \mathrm{mg} / \mathrm{kg}$ per day. Not only does $C L_{\mathrm{TB}}$ fall, but the hepatic extraction ratio falls so that at high dose rates given into the hepatic artery, much of the regional specificity may be lost (Ensminger et al., 1978a, 1983).

The administration of a second agent can decrease the total body clearance and make a given agent less advantageous regionally. For example, the administration of thymidine with FU can decrease the clearance of Fu greatly and virtually eliminate any selectivity for hepatic arterial FU (Kirkwood et al., 1980). 
As the equations above indicate, the concentration of drug in the arterial watershed is dependent upon the blood flow rate through the infused artery (assuming high total body drug clearance). For example, decreasing the blood flow rate by $90 \%$ should increase the arterial concentrations of drug at any given dose rate by about 10 -fold. There are at least five methods to decrease arterial blood flow. Note that as arterial blood flow is decreased, it may become difficult to dissociate therapeutic effects due to resultant ischemia from therapeutic effects due to increased drug exposure to the tumor. The five methods for decreasing arterial blood flow are best illustrated as applied to hepatic arterial infusion.

Ligation of the hepatic artery with placement of a catheter in the distal arterial stump is one method to simultaneously decrease blood flow to the tumor while exposing the tumor to higher drug concentrations (Ramming et al., 1976; Karakousis et al., 1979). In general, the results of this manoeuver are marginally advantageous over intraarterial drug infusion alone. Rapid collateralization from a multiplicity of vessels as well as thrombosis in the stump around the catheter diverts drug flow to only a small portion of the liver. The application of low flow nuclide angiography using injection of a lung scanning agent (Tc99m-macroaggregated albumin or TcMAA) through the catheter in such studies can document the drug flow distribution as well as thrombus formation (Kaplan et al., 1978; Ensminger et al., 1981a). Ligation has the added drawback of being irreversible. Recently a method using operatively positioned strangulation slings on the hepatic artery has been examined as a means to produce transient occlusion of the hepatic artery for up to $16 \mathrm{hr}$ (Dahl et al., 1981). Intraarterial FU was given concurrently in some of the patients undergoing transient hepatic arterial occlusion with this method. The procedure apparently was well tolerated and permanent arterial thombosis due to the temporary occlusion did not occur.

A second method, usually inadvertant, of decreasing hepatic arterial blood flow, comes with clot formation around the indwelling catheter. Clot formation may decrease blood flow dramatically prior to total occlusion. This should generate significantly increased drug levels in the infused watershed as the formula above would suggest. Such clot formation is frequent with the use of percutaneous angiographic catheters (Clouse et al., 1977). One recent study noted an improved response rate in those patients where hepatic arterial occlusion occurred at some point in their therapy (Patt et al., 1981). This method of decreasing the hepatic arterial blood flow is essentially uncontrolled and irreversible. Partial occlusion proceeds to total occlusion haphazardly. Once there is total occlusion no further hepatic arterial chemotherapy is possible even in patients where a response has occurred. With total occlusion, collaterization occurs rapidly so that tumor is still well nourished from a multiplicity of alternate arterial sources (Bengmark and Rosengren, 1970). Such patients will often die of progressive hepatic tumor once the therapeutic effect of thrombosis has been lost.

A third method for temporary reduction of hepatic arterial blood flow has been the use of balloon catheters (Watkins et al., 1960; Cho et al., 1983). Important factors to be considered are the degree of obstruction (determined by vessel size and the degree of balloon inflation) and the duration of the blood reduction induced by balloon inflation. If the reduction of flow can be controlled and quantitated, balloon catheters might prove very useful in those regimens where short infusions or bolus injections are given. Additional considerations with such regimens are the appropriateness of the drug-schedule (see below) and the flow distribution changes brought about by reducing overall hepatic arterial blood flow.

A fourth method for reducing hepatic arterial blood flow has been the infusion of vasoconstricting agents such as epinephrine, angiotensin or vasopressin. Such agents have been used extensively in pharmacoangiography to better delineate tumor vessels (Abrams, 1964). The lack of responsive smooth muscle fibers in the wall of tumor vessels provides at least the potential for redirecting blood flow from normal liver (responsive arterioles) to tumor (non-responsive arterioles) (Hafstrom et al., 1980). Vasoconstricting agents may have great impact, additionally, in reducing overall hepatic arterial flow. Direct arterial infusion of appropriate concentrations of epinephrine or vasopressin may confine the 
vasoconstriction to the hepatic arterial watershed. In our experience, as little as $1 \mu \mathrm{g}$ of epinephrine given into the hepatic artery can totally block the hepatic arterial blood flow in some patients for as long as 5 min without affecting baseline pulse and blood pressure. Contingent upon the pharmacokinetic principle delineated previously, concurrent cytotoxic drug administration while blood flow is reduced should generate higher arterial drug levels and thus a greater regional tumor exposure. It should be noted that when vasoconstrictors decrease overall flow to the normal liver, systemic drug exposure may actually increase for agents with insignificant hepatic extraction (Iwaki et al., 1978). Thus, studies involving concurrent vasoconstrictors and cytotoxic agents will need extensive monitoring to assure appropriate dose-schedules for maximal tumor exposure without loss of regional selectivity due to decreased hepatic extraction.

A fifth method for decreasing hepatic arterial blood flow is the use of microparticulates or microspheres. At sufficiently high doses approximating 90 million biodegradable starch microspheres ( $40 \mu \mathrm{m}$ diameter), hepatic arterial blood flow can be totally blocked in about $25 \%$ of patients (Aronsen et al., 1979; Lindell et al., 1978; Dakhil et al., 1982). By 30 min after hepatic arterial injection, the starch microspheres are completely lysed by serum amylase and flow resumes relatively normally through the hepatic arterial tree as ascertained by contrast angiograms. In the remaining $75 \%$ of patients, hepatic arterial flow decreases by $80 \%$ and arterial-venous shunting occurs. As will be described below, the use of the hepatic arterial starch microspheres may be an additional method to deliver more drug to tumors within the liver.

\subsection{Tumor Vasculature and BloOd Flow}

Based on the radiographic appearances using contrast angiography, it has been customary to regard tumors as being either hypo- or hyper-vascular relative to normal liver. As tumor nodules grow, the evoked new capillary bed develops at the periphery so that the most vascularized area is the outer shell of the nodule (Warren, 1979). Although the central core of many tumor nodules in the liver is hypovascular, the periphery of the tumor nodule is generally hypervascular relative to normal liver as demonstrated by nuclear tomographic scans after hepatic arterial injection of TcMAA (Gyves et al., $1982 \mathrm{~b}, \mathrm{c})$. The microvascular pattern is consistent with the distribution of tumor cell viability and growth, the central core of the tumor often being necrotic while the peripheral rim of actively proliferating tumor cells has an excellent blood supply (Ackerman and Hechmer, 1980; Warren, 1979). The presence or absence of a hypovascular core appears to relate more to the size of the tumor nodule than to tumor type (Gyves et al., 1982c). Nodules below $8 \mathrm{~cm}$ in diameter are uniformly hypervascular whereas those over $9 \mathrm{~cm}$ in diameter display a hypovascular rim as ascertained by radionuclide tomographic angiography. The density of vessels in the hypervascular regions of tumor nodules appears to be 2-8 fold greater than in normal liver. These observations suggest a number of methods whereby tumor hypervascularity can be used for selective therapeutic advantage.

Tumor vessels tend to lack the smooth muscle layer found in normal precapillary arterioles and thus are less sensitive to vasoconstricting agents such as epinephrine or vasopressin (Hafstrom et al., 1980; Mattson et al., 1979). If a relative redistribution of blood flow occurs with vasoconstricting agents, it may provide a selective advantage in the delivery of therapeutic microspheres to hypervascular tumor. Microspheres of $40-80 \mu \mathrm{m}$ diameter when injected as a homogenous suspension into the hepatic artery should lodge in the hepatic arterial microvasculature in direct proportion to regional blood flow throughout that watershed. As mentioned earlier, the hepatic arterial injection of TcMAA (lung scanning agent) with nuclear tomography provides a means to determine the relative blood flow distribution between normal liver and tumor nodules within liver and thus to monitor selective delivery of therapeutic microspheres to tumor (Gyves et al., 1982b).

\subsubsection{Therapeutic (Drug and Radiation) Microspheres}

Three varieties of microspheres have been used clinically, two for drug delivery (chemoembolization) and one for radiotherapy. Ethylcellulose microspheres which are 
$225 \pm 55 \mu \mathrm{m}$ in diameter and contain $80 \%$ by weight of biologically active mitomycin $\mathrm{C}$ have undergone recent testing in Japan (Kato et al., 1980, 1981). Preclinical investigations in dogs indicate that drug release occurs over hours and that there is an approximate $60 \%$ reduction in circulating systemic mitomycin when mitomycin is encapsulated in microspheres and administered intraarterially (Kato et al., 1980). In clinical studies, minor responses were seen in a small number of patients with regional tumors (Kato et al., 1981). Ethylcellulose microspheres are not biogradable and thus should permanently occlude the vessel in which they lodge. Hence, the potential therapeutic effects would result from a combination of infarction and prolonged, intensified drug exposure.

As previously mentioned, another approach using biodegradable starch microspheres has been developed recently (Aronsen et al., 1979; Lindell et al., 1978; Dakhil et al., 1982). The concurrent hepatic arterial injection of a suspension of starch microspheres in a drug solution has the potential of temporarily holding the drug solution in the hepatic arterial capillary bed thus allowing more time for the higher drug concentration to move into surrounding tissue. Bischlorethylnitrosourea (BCNU) and mitomycin $\mathrm{C}$ have been examined in conjunction with starch microspheres given via the hepatic artery (Dakhil et al., 1982; Gyves et al., 1982d). These agents were chosen due to their rapid tissue uptake and mechanism of action as alkylating agents (i.e., peak drug levels are important). Due to increased drug delivery to the liver and hepatic tumor, systemic drug exposure was reduced up to $90 \%$ for $\mathrm{BCNU}$ and $50 \%$ for mitomycin $\mathrm{C}$ when drug was given with starch microspheres versus drug injection alone. In hypervascular regions of tumors, more drug solution should be held up as compared to the drug entrapment in less vascular regions of normal liver. As the microspheres are digested, their diameter progressively decreases (from $40 \mu \mathrm{m}$ initially) and the drug column moves distally into the capillary bed. Due to complete dissolution of the starch microspheres by 30 min post-injection, subsequent doses can be administered without destroying access to the tumor microcirculation. Repeated dosage studies and clinical trials comparing hepatic arterial BCNU and mitomycin with and without starch microspheres are in progress.

Yttrium-90 resin microspheres with a $55 \mu \mathrm{m}$ diameter have been used both in model systems (Blanchard et al., 1965) and in the clinic to treat hepatic tumors with internal radiotherapy (Abel, 1965; Grady, 1979). In the Walker carcinosarcoma rat liver tumor, yttrium-90 microspheres lodge in highest concentrations in the hypervascular tumor periphery (Ackerman and Heckmer, 1980). Concurrent epinephrine administration decreases yttrium-90 microsphere concentration in normal liver and markedly increases concentrations in the tumor in this rat model. In several patients, metastatic tumors were found to have 3-4-fold higher yttrium-90 microsphere levels than normal liver (Grady, 1979; Grady et al., 1980). Yttrium-90 microspheres have a short effective kill distance of 2-3 $\mathrm{mm}$ and deliver the majority of their dose over about 3 days. Tomographic nuclear angiography (see above) with TcMAA may be essential to the safe use of yttrium as well as starch microspheres in that the therapeutic microspheres must go to the tumor for efficacy and not to the stomach, duodenum, or lungs if severe toxicity is to be prevented.

5-Bromo-2'deoxyuridine (BUDR) is an analogue of thymidine which is incorporated solely and specifically into the DNA of replicating cells. BUDR undergoes debromination in the liver, and in analogy with fluorodeoxyuridine and thymidine (Ensminger et al., 1978a; Ensminger and Frei, 1978), can be expected to have high hepatic extraction. BUDR has pharmacokinetic properties including a high total body clearance $(5-15 \mathrm{l} / \mathrm{min})$ making it suitable to hepatic arterial infusion for selective regional effects (Schwade et al., 1981). BUDR by hepatic arterial infusion should be incorporated selectively into proliferating tumor within the liver since there is usually little hepatic parenchymal DNA synthesis. For maximum incorporation of BUDR into DNA, prolonged exposure is necessary (Djordjevec and Szbalski, 1960; Sano et al., 1968; Schindler et al., 1966). Such prolonged exposure should be possible using the totally implanted system for hepatic arterial infusion described below. With sufficient incorporation into both strands of DNA, radiation sensitivity can be increased at least 2-fold. Studies with BUDR and yttrium-90 microspheres have not been done, but the combination would be expected to have considerable 
selective antitumor potential. Preclinical studies with this combination are in progress. The implanted system should allow continuous infusion of BUDR via the central pumping mechanism whereas the pump sideport can be utilized for yttrium-90 microsphere injection. Further selectivity using both starch and yttrium microspheres may be possible through the concurrent administration of vasoconstrictors to shift flow from normal liver into the tumor microcirculation.

\subsection{DOSE RESPONSE}

The second element in the evaluation of the appropriateness of a drug for hepatic arterial chemotherapy is the dose-response curve for that drug in the tumor type in question. By arterial infusion one attempts to expose the tumor to more drug than is otherwise possible. However, if the tumor is extremely sensitive to a given drug, then the exposure with intravenous chemotherapy may be sufficient to kill the entire sensitive cell population. If, on the other hand, the tumor is absolutely resistant to the drug, then even increasing the exposure by a hundred-fold, as is possible with hepatic arterial infusion of some drugs (Table 2), may not produce noticeable antitumor response. If an agent is reported to have marginal activity when given intravenously in a particular tumor, then exploiting the dose-response curve through hepatic arterial infusion may be profitable (Frei and Canellos, 1980). For example, FU and FUDR both have definite, but marginal activity, in colorectal cancer. Hence, generating a marked increase in exposure by hepatic arterial infusion of FU or FUDR is more likely to be of benefit than the use of another agent, such as cytosine arabinoside, which has essentially no activity in this disease (although the use of cytosine arabinoside would be appropriate pharmacokinetically).

When the dose-response for an agent is sufficiently steep and the pharmacokinetics appropriate, it should be possible to generate cytotoxic drug levels in the hepatic arterial tree with lower, non-toxic systemic levels. In fact, this should be reflected in the toxicity observed, i.e. dose-limiting toxicity should be regional (liver), and not systemic (bone marrow or gut). It should be noted that the doses and schedules of agents can be so selected as to achieve maximum tolerated systemic levels with supramaximal effects on the tumor in the liver. For example, this is possible with FU due to its $50-80 \%$ hepatic extraction (Ensminger et al., 1978a, 1983). Three times the systemic dose can be given by the hepatic artery to achieve at least a 50 -fold increased exposure to the liver tumor, yet the same systemic exposure (to extrahepatic tumor) occurs as is produced by intravenous infusion.

\subsection{Schedule Dependency}

A third consideration is the drug's schedule dependency which is best defined in preclinical animal and cell culture experiments (Blum et al., 1982). Schedule dependency is based on the biochemical and cytokinetic actions of the agents in question. For example, in the case of alkylating agents, bolus injections for short term peak exposure may produce maximal damage to the nucleic acids of cells. Lower drug levels with constant infusions can allow rate-limited repair processes to occur more efficiently and thereby prevent lethality (Skipper and Schabel, 1982). Alternatively, antimetabolites generally produce cytotoxicity as a function of duration of exposure above a given concentration (Chabner and Young, 1973). The drug schedule dictates the type of delivery system necessary. Prolonged controlled infusions will require a pumping system. Short infusions or boluses may be given by hand injection or by a temporary pump attachment.

\subsection{AdequaCY of IntraArterial Infusion}

There are several difficulties unique to intraarterial chemotherapy which are not found with systemic, intravenous drug administration. Although a drug may be pharmacologically rational, it must be delivered directly into the tumor blood supply in a reliable and reproducible manner. For example, with protracted (i.e., greater than 3 weeks) hepatic arterial infusion using percutaneous angiographic catheters or surgically placed plastic catheters, progressive hepatic arterial thrombosis occurs at a high rate and gradually produces decreased blood flow and ultimately occlusion (Cady, 1973; Clouse et al., 1977). 
Any improvement in response (Patt et al., 1981) (brought about through resultant ischemia and higher drug levels generated) must be tempered by the inability to use further arterial chemotherapy. It also has been shown that the pattern of distribution of agents injected intraarterially is dependent upon the flow rate of the infusion (Kaplan et al., 1978). Radionuclide angiography using Tc99m-macroaggregated albumin (TcMAA) appears to give the best representation of drug distribution at the low infusion rates $(3-1000 \mathrm{ml}$ per day) clinically used (Kaplan et al., 1980). When percutaneous angiographic catheters are used, the tip of the catheter tends to move about and leads to frequent and unpredictable flow distribution changes. In hepatic arterial infusions, when drug is infused inadvertently into a gastric artery, severe gastric damage can result (Chuang et al., 1981; Narsete et al., 1977). Hence, a catheter system free of thrombosis and movement which reliably infuses only the tumor containing region or organ is a prerequisite for maximum response with minimal toxicity. The more potent the cytotoxic agent for intraarterial use, the more important the focusing of the flow from the catheter. Surgical placement of soft silastic catheters in a manner to minimize turbulence in blood flow represents the most durable intraarterial access at present. Nuclide angiography to guide in catheter placement and to ascertain complete drug flow distribution is equally important (Yang et al., 1982).

\subsection{Drug Delivery Systems For Intraarterial Use}

Intraarterial drug infusions have been limited by the type of pumping system involved. Pumps worn externally by patients have proven inconvenient because of their bulkiness and have been a major hindrance to normal daily activities. The pump and the external catheter connection have represented sites for the interruption of the infusion path leading to bleeding, catheter thrombosis, or infection from the introduction of pathogenic organisms. The fact that patients have undergone protracted outpatient treatment using external pumps is witness more to the fortitude of the patient than to the ingenuity of their physicians and the biomedical engineers. The need for multiple supportive personnel to maintain prolonged outpatient infusions and the clumsiness and unreliability of the infusion systems has limited their widespread applicability.

A totally implanted drug delivery system tested over the past several years appears to overcome many of the problems noted above and has been applied to intraarterial infusional therapy of head and neck cancer (Baker et al., 1981), brain tumors (Phillips $e t$ al., 1982), and liver cancer (Ensminger et al., 1981a; Buchwald et al., 1980). The most extensive experience has been with hepatic arterial chemotherapy where, at laparotomy, a small flexible silastic catheter is implanted so as to infuse the entire liver. Appropriate vessels are ligated in an effort to confine drug flow to the liver (Niederhuber and Ensminger, 1983). The catheter is attached to a subcutaneously placed Model 400 Infusaid pump (Fig. 1). In the first 60 patients with colorectal cancer metastatic to liver treated with this system at the University of Michigan, there was only one hepatic artery occlusion (immediately post-operatively) and one permanent catheter occlusion (Ensminger et al., 1982). Flow distribution to the entire liver ascertained by radionuclide angiography was maintained in the other 58 patients. Autopsies in six patients having catheters in place for up to 18 months showed no evidence of thrombosis or vessel wall damage in the catheterized artery. These patients as a group received 13,000 cumulative days of hepatic arterial infusion and 900 pump refills without a bleeding or infectious episode. Over $95 \%$ of the days of infusion were given as outpatients. Patients were able to function relatively normally since the system was totally implanted under the skin. This system has been found to function reliably for other investigators as well (Barone et al., 1982). The model 400 Infusaid pump has a sideport allowing direct injection into the hepatic artery catheter. The $0.63 \mathrm{~mm}$ lumen on the hepatic arterial catheter readily allows the passage of TcMAA, starch microspheres and other forms of microspheres. The recent approval by the Food and Drug Administration of the Infusaid pump for hepatic arterial infusion with FUDR has facilitated dissemination of the device.

Preliminary therapeutic results in the treatment of hepatic cancers have been excellent with the implanted system (Ensminger et al., 1982). The Model 400 Infusaid pump holds 
$50 \mathrm{ml}$ of solution with a typical flow rate of $2-3 \mathrm{ml} /$ day and, for hepatic arterial chemotherapy, pumps are refilled every two weeks, alternating two weeks of FUDR $(0.3 \mathrm{mg} / \mathrm{kg}$ per day) with two weeks of saline in order to decrease the propensity for chemical hepatitis. Hepatic tumor response ascertained by physical examination and liver scan using standard criteria was seen in $50 / 60$ ( $83 \%$ of patients). Only one patient had progessive growth of liver metastases. Response durations to initial FUDR therapy ranged from 2 to $24+$ months. Hepatic arterial mitomycin through the pump sideport was added to FUDR when response was no longer evident or when extrahepatic disease became manifest. Ninety-eight percent (47/48) of patients with an elevated carcinoembryonic antigen level had at least a $50 \%$ fall in levels with treatment. Median survival by life table analysis for patients with diseases confined to the liver at operation has been 24 months. For patients with disease outside of the liver, median survival has been 8-10 months. Toxicities were all reversible and consisted of mild gastritis in $56 \%$ of patients, ulcers in $8 \%$, and, anicteric (23\% of patients) and icteric (23\% of patients) hepatitis. With dose-schedule modifications, all patients showing toxic effects were able to continue treatment without recurrence of toxicity.

In situations where repeated arterial access is required for boluses or short infusions, it may not be necessary to implant the infusion pump. Implantable injection ports attached to silastic catheters can be used (Gyves et al., 1982a). Such ports are much less expensive, less noticeable, and generally do not require frequent flushing between uses.

\section{SUMMARY}

Recent developments have made regional chemotherapy a more rational endeavour. The important pharmacokinetic principles have been defined. The increase in regional exposure achieved is a direct function of a drug's total body clearance and is an inverse function of the permeability-area product (defining ease of egress) for third spaces or of the regional arterial blood flow for intraarterial infusion. Agents having appropriate properties are available. For new agents with appropriate pharmacokinetic parameters, regional chemotherapy may provide a means to examine the dose response against measurable tumors in the regions in question.

The observation that most tumors are hypervascular may be crucial to the development. of selective treatments using microspheres to deliver therapy in direct proportion to the density of the microvasculature. Regionally infused vasoconstrictors (epinephrine, angiotensin) may allow shunting of flow away from normal tissue toward tumor without potentially serious systemic cardiovascular effects. Investigations and applications of regional chemotherapy have been fostered immensely by the reliably and convenience of the Infusaid implantable pump and by implantable injection ports. The problem of systemic failure with regional approaches still remains but is approachable using pharmacologically rational programs aimed at delivering maximal systemic chemotherapy along with regional treatment. In hepatic arterial therapy, in particular, a randomized prospective study is being considered to examine the impact of such combined treatment versus regional therapy alone and versus systemic chemotherapy alone for metastatic colorectal cancer to liver. Thus, the future for regional chemotherapy appears exciting. There are many opportunities to apply therapeutic principles rationally with the potential of significant benefit to many patients.

Acknowledgements - Support for the authors' investigations into regional chemotherapy was provided by NIH grants CA28478 and CA28583 and by the Burroughs-Wellcome Fund. The skilled technical assistance of P. Stetson, M. Janis, S. Walker, S. Gilbertson, C. Knutsen, R. Castello and B. Castello is appreciated. The collaboration of John Niederhuber, M.D., Chief of Oncologic Surgery and of William Chandler, M.D., Associate Professor of Neurosurgery at the University of Michigan was essential to the research performed.

\section{REFERENCES}

ABEL, I. M. (1965) Treatment of inoperable primary pancreatic and liver cancer by the intra-arterial administration of radioactive isotopes ( $Y^{99}$ radiating microspheres). Ann. Surg. 162: 267-278. 
Abrams, H. L. (1964) The response of neoplastic renal vessels to epinephrine in man. Radiology 82: 217-224.

ACKerman, N. B., Lien, W. M., Kondi, E. S. and Silverman, N. A. (1969) The blood supply of experimental liver metastases. I. The distribution of hepatic artery and portal vein blood to "small" and "large" tumors. Surgery 66: 1067-1072.

Ackerman, N. B. and Heckman, P. A. (1980) The blood supply of experimental liver metastases. V. Increased tumor perfusion with epinephrine. Am. J. Surg. 140: 625-631.

Aronsen, K. F., Hellekant, C., Holmberg, J., Rothman, U. and Tedu, H. (1979) Controlled blocking of hepatic artery flow with enzymatically degradable microspheres combined with oncolytic drugs. Eur. Surg. Res. 11: 99-106.

Baker, S. R., WheEler, R. H., EnSMinger, W. D. and Niederhuber, J. E. (1981) Intraarterial infusion chemotherapy for head and neck cancer using a totally implantable infusion pump: A preliminary report. Head Neck Surg. 4: 118-124.

Barone, R. M., Byfield, J. E., Goldfarb, P. B., Frankel, S., Ginn, C. and Greer, S. (1982) Intra-arterial chemotherapy using an implantable infusion pump and liver irradiation for the treatment of hepatic metastases. Cancer 50: 850-862.

Bengmark, S. and Rosengren, K. (1970) Angiographic study of the collateral circulation to the liver after ligation of the hepatic artery in man. Am. J. Surg. 19: 620-624.

Blackshear, P. J., Dorman F. D., Blackshear, P. J. Jr., Varco, K. L. and Buchwald, H. (1970) A permanently implantable self-recycling low flow constant rate multipurpose infusion pump of simple design. Surg. Forum 21: 136.

Blanchard, R. J. W., Grotenhuis, I., Lafare, J. W. and Perry, J. F. (1965) Blood supply to hepatic V2 carcinoma implants as measured by radioactive microspheres. Proc. Soc. exp. Biol. Med. 118: 465-468.

BLEYER, W. A. and Dedrick, R. L. (1977) Clinical pharmacology of intrathecal methotrexate. 1. Pharmacokinetics in nontoxic patients after lumbar injection. Cancer Treat. Rep. 61: 703-708.

Bleyer, W. A. and POPLACK, D. G. (1978) Clinical studies of the central nervous system pharmacology of methotrexate. In: Clinical Pharmacology of Anti-Neoplastic Drugs, pp. 115-131, Pinedo, H. M. (ed.). Elsevier/North Holland Biomedical Press.

Bleyer, W. A., Poplack, D. G., Simon, R. M., Henderson, E. S., Leventhal, B. G., Zeigler, J. L., Levine, A. S. and Ommaya, A. K. (1978) "Concentration $\times$ time" methotrexate via a subcutaneous reservoir: a less toxic regimen for intraventricular chemotherapy of central nervous system neoplasma. Blood 50: 835-842.

Blum, R. H., Frei, E. III and Holland, J. F. (1982) Principles of dose, schedule and combination chemotherapy. In: Cancer Medicine, pp. 730-752, Holland, J. and FreI, E. III (eds). Lea and Febiger, Philadelphia.

Brefis, C. and Young, G. (1954) Blood supply of neoplasma in the liver. Am. J. Path. 30: 969-985.

Buchwald, H., Grages, T. B., Vassilopoulos, P. P., Rohde, T. D., Varco R. L. and Blackshear, P. J. (1980) Intraarterial infusion chemotherapy for hepatic carcinoma using a totally implantable infusion pump. Cancer 45: 866-869.

Buchwald, H., Barbosa, J., Varco, R. L., Rohde, T. D., Rupp, W. H., Schwartz, R. A., Goldenberg, F. J., Rublein, T. G. and Blackshear, P. J. (1981) Treatment of a type II diabetic by a totally implantable insulin infusion device. Lancet i: 1233-1234.

CADY, B. (1973) Hepatic arterial patency and complications after catheterization for infusion chemotherapy. Ann. Surg. 178: $156-158$

Chabner, B. A. and Young, R. C. (1973) Threshold methotrexate concentration for in vivo inhibition of DNA synthesis in normal and tumorous target tissues. J. clin. Invest. 52: 1804-1811.

Chen, H. S. G. and Gross, J. F. (1980) Intra-arterial infusion of anticancer drugs: Theoretic aspects of drug delivery and review of responses. Cancer Treat. Rep. 64: 31-40.

Cho, K. J., Ensminger, W. D., Shields, J. J. and Adams, D. F. (1983) Selective tissue ablation by pharmacoangiography. In: Angiography, ABrams, H. L. (ed.). Little, Brown and Co., Boston (In press).

Chuang, V. P., Wallace, S., Stroehlein, J., Yap, H. Y. and Patt, Y. Z. (1981) Hepatic artery infusion chemotherapy: Gastroduodenal complication. Am. J. Roentgenol. 137: 347-350.

Clouse, M. E., Ahmed, R., Ryan, R. B., Oberfield, R. A. and McCaffrey, J. A. (1977) Complications of long term transbrachial hepatic arterial infusion chemotherapy. Am. J. Roentgenol. 129: 799-803.

Collins, J. M., Dedrick, R. L., KIng, F. G., SPeYer, J. L. and Myers, C. E. (1980) Nonlinear pharmacokinetic models for 5-fluorouracil in man: Intravenous and intraperitoneal routes. Clin. Pharmac. Ther. 28: 235-246.

Dahl, E. P., Fredlund, P. E., Tylen, U. and Bengmark, S. (1981) Transient hepatic dearterialization followed by regional intraarterial 5-fluorouracil infusion as treatment for liver tumors. Ann. Surg. 193: 82-88.

Dakhil, S., Ensminger, W. D., Cho, K., Niederhuber, J., DoAn, K. and Wheeler, R. (1982) Improved regional selectivity of hepatic arterial BCNU with degradable microspheres. Cancer 50: 631-635.

Dakhil, S., Ensminger, W. D., Kindt, G., Niederhuber, J., Chandler, W., Greenberg, H. and Wheeler, R. (1981a) Implanted system for intraventricular drug infusion in central nervous system tumors. Cancer Treat. Rep. 65: 401-411.

Dakhil, S., Ensminger, W. D., Strother, V., Kindt, G., Chandler, W. F. and Greenberg, H. S. (1981b) Pharmacokinetics of intraventricular 5-fluoro-2'-deoxyuridine (FUDR) in patients with menigeal neoplasia. Proc. Am. Ass. Cancer Res. 22: 178.

Dedrick, R. L., Myers, R. L., Bungay, P. M. and DeVita, V. T. JR. (1978) Pharmacokinetic rational for peritoneal drug administration in the treatment of ovarian cancer. Cancer Treat. Rep. 62: 1-11.

DjoRdjevic, B. and Syzbalski, W. (1960) Genetics of human cell lines. III. Incorporation of 5-bromo- and 5 -iododeoxyuridine into the deoxyribonucleic acid of human cells and its effects on radiation sensitivity. $J$. exp. Med. 112: 509-531.

Eckman, W. W., Patlak, C. S. and Fenstermacher, J. D. (1974) A critical evaluation of principles governing the advantages of intraarterial infusions. J. Pharmacokinet. Biopharm. : 257-285.

ENSMINGER, W. D. and FreI, E. III (1978) High-dose intravenous and hepatic artery infusions of thymidine. Clin. Pharmac. Ther. 24: 610-615.

Ensminger, W. D., Rosowsky, A., Raso, V., Levin, D. C., Glode, M., Come, S., Steele, G. and Frei, E. III 
(1978) A clinical pharmacological evaluation of hepatic arterial infusions of 5-fluoro-2'-deoxyuridine and 5-fluorouracil. Cancer Res. 38: 3784-3792.

Ensminger, W. D., Thompson, M., Come, S. and Egan, E. M. (1978b) Hepatic arterial BCNU (NSC-409962): A pilot clinical pharmacologic study in patients with liver tumors. Cancer Treat. Rep. 62: 1509-1512.

Ensminger, W. D., Niederhuber, J., Dakhil, S., Thrall, J. and Wheeler, R. (1981a) Totally implanted drug delivery system for hepatic arterial chemotherapy. Cancer Treat. Rep. 65: 393-400.

Ensminger, W. D., Dakhil, S., Doan, K., Cho, K., Wheeler, R. and Pollard, H. M. (1981b) Clinical pharmacology of dichloromethotrexate in hepatic arterial infusions. Proc. Am. Ass. Cancer Res. 22: 271.

Ensminger, W. D., Niederhuber, J., Gyves, J., Thrall, J., Cozzi, E. and Doan, K. (1982) Effective control of liver metastases from colon cancer with an implanted system for hepatic arterial chemotherapy. Proc. Am. Ass. Cancer. Res. 1: 94.

Ensminger, W. D., Stetson, P., Gyves, J., Walker, S., Janis, M., Zlotecki, R., Mayer, M., Brady, T. and NIEDERHUBER, J. (1983) Dependence of hepatic arterial fluorouracil pharmacokinetics on dose rate and duration of infusion. Proc. Am. Soc. clin. Oncol. 2: (In press).

FRei, E. III and CANellos, G. P. (1980) Dose: A critical factor in cancer chemotherapy. Am. J. Med. 69: 585-594.

GraDY, E. (1979) Internal radiation therapy of hepatic cancer. Dis. Col. React. 22: 371-375.

Grady, E. D., Auda, S. P. and CheEK, W. V. (1980) Vasoconstrictors to improve localization of radioactive microspheres to treat liver cancer. Presented at the: 1980 Medical Association of Georgia Scientific Assembly (Georgia Chapter, American College of Surgeons) November 21, 1980, Atlanta, Georgia.

Greenberg, H. S., TARen, J., Ensminger, W. D. and Doan, K. (1982) Benefit from and tolerance to continuous intrathecal infusion of morphine for intractable cancer pain. $J$. Neurosurg. 57: 360-364.

Gutin, P. H., Weiss, H. D., WIERnik, P. H. and WALKer (1976) Intrathecal $\mathbf{N}^{\prime} \mathbf{N}^{\prime}, \mathbf{N}^{\prime \prime}$-triethyienethiophosphoramide [Thio-Tepa (NSC 6396)] in the treatment meningeal disease. Cancer 38: 1471-1475.

Gyves, J. W., Ensminger, W. D., Nifderhuber, J., Liepman, M., Cozzi, E., Doan, K., Dakhil, S. and Wheeler, R. (1982a) Totally implanted system for intravenous chemotherapy in patients with cancer. Am. J. Med. 73: $841-858$

Gyves, J., Ensminger, W. D., Yang, P., Thrall, J. and Cho, K. (1982b) Clinical utility of microspheres to assess and attack hepatic tumor microcirculation. Clin. Res. 30: 418A.

Gyves, J., Ensminger, W. D., Thrall, J., Cho, K. and Walker, S. (1982c) Dependence of hepatic tumor vascularity on tumor size. Clin. Res. 30: 747A.

Gyves, J., Ensminger, W. D., VanHarken, D., Niederhuber, J., Knutsen, C. and Doan, K. (1982d) Improved regional selectivity of hepatic arterial mitomycin $\mathrm{C}$ by starch microspheres. Proc. Am. Ass. Cancer Res. 23: 137.

Gyves, J., Ensminger, W. D., Niederhuber, J., Manuszak, P., VanHarken, D., Janis, M., Stetson, P., KNUtsen, C. and DoAn, K. (1982e) Phase I study of intraperitoneal (IP) 5 day continuous 5-FU infusion and bolus mitomycin C. Proc. Am. Ass. clin. Oncol. 1: C-59.

Gyves, J., Ensminger, W. D., Stetson, P., Vanharken, D., Janis, M., Cho. K., Meyer, M., Walker, S., GiLber TSON, S. and NiEDERHUBER, J. (1983) Clinical pharmacology of mitomycin C (mito) by hepatic arterial (HA) infusion. Proc. Amer. Soc. Clin. Oncol. (In press).

Hafstrom, L., Nobin, A., Persson, B. and Sundqvist, K. (1980) Effects of catecholamines on cardiovascular response and blood flow distribution to normal tissue and liver tumors in rats. Cancer Res. 40: $481-485$.

Howell, S. B., Chu, B. B. F., Wung, W. E., Metha, B. M. and Mendelsohn, J. (1981) Long-duration intracavitary infusion of methotrexate with systemic leucovorin protection in patients with malignant effusions. J. clin. Invest. 67: 1161-1170.

Iwaki, A., NAGASUE, N., Kobayoshi, M. and InoKuchi, K. (1978) Intraarterial chemotherapy with concomitant use of vasoconstrictors for liver cancer. Cancer Treat. Rep. 62: 145-146.

Kaplan, W. D., D’Orsi, C. J., Ensminger, W. D., Smith, E. H. and Levin, D. C. (1978) Intraarterial radionuclide infusion: A new technique to assess chemotherapy perfusion patterns. Cancer Treat. Rep. 62: 669-703.

Kaplan, W. D., Ensminger, W. D., Come, S. E., Smith, E. H., D’Orsi, C. J., Levin, D. C., Takvorian, R. W. and SteELE, G. D. JR. (1980) Radionuclide angiography to predict patient response to hepatic artery chemotherapy. Cancer Treat. Rep. 64: 1217-1222.

Karakousis, C. P., Douglas, H. O., JR. and Holyoke, E. D. (1979) Technique of infusion chemotherapy, ligation of the hepatic artery and dearterialization in malignant lesions of the liver. Surg. Gynecol. Obstet. 149: $403-407$.

Kato, T., Nemoto, R., MoRI, H. and KumagaI, I. (1980) Sustained-release properties of microencapsulated mitomycin $C$ with ethylcellulose infused into the renal artery of the dog kidney. Cancer 46: 14-21.

Kato, T., Nemoto, R., Mori, H., Takahashi, M. and Harada, M. (1981) Arterial chemoembolization with mitomycin $\mathrm{C}$ microcapsules in the treatment of primary or secondary carcinoma of the kidney, liver, bone and intrapelvic organs. Cancer 48: 674-680.

Kelsen, D. P., Hoffman, J., Alcock, N., Chen, E., Golbey, R. B., Young, C. W. and Fortner, J. (1980) Pharmacokinetics of regional infusion of cisplatin. Proc. Am. Ass. Cancer Res. 21: 745.

KirkwoOd, J., Ensminger, W. D. and Rosowsky, A. (1980) 5-Fluorouracil and thymidine: Pharmacokinetic observations in a phase I trial comparing 5-fluorouracil and 5-fluorouracil with concurrent thymidine infusions. Cancer Res. 40: 107-113.

Latham, F. JR. and Foster, J. H. (1967) Hepatic resection for metastatic cancer. Am. J. Surg. 113: 551-557.

Lindell, B., Aronsen, K. F., Nosslin, B. and Rothman, U. (1978) Studies in pharmacokinetics and tolerance of substance temporarily retained in the liver by microspheres embolisation. Ann. Surg. 187: 95.

Mattsson, J., Appelgren, L., Hamberger, B. and Peterson, H. T. (1979) Tumor vessel innervation and influence of vasoactive drugs on tumor blood flow, In: Tumor blood Circulation: Angiogenesis, Vascular Morphology and Blood Flow of Experimental and Human Tumors, pp. 129-141. PETERSON, H. I. (ed.). CRC Press, Inc., Florida. 
Narsete, T., Ansfield, F., Wirtanen, G., Ramirez, G., Wolberg, W. and Jarrett, F. (1977) Gastric ulceration in patients receiving intrahepatic infusion of 5-fluorouracil. Ann. Surg. 188: 734-736.

NiEDERHUBER, J. and ENSMINGER, W. D. (1983) Surgical considerations in the management of hepatic neoplasia. Sem. Onc. (In press).

Ozols, R. F., Young, R. C., Speyer, J. L., Sugarbaker, P. H., Greene, R., Jenkins, J. and Meyers, C. E. (1982) Phase I and pharmacological studies of adriamycin administered intraperitoneally to patients with ovarian cancer. Cancer Res. 42: 4265-4269.

Patt, Y. Z., Wallace, S., Freireich, E. J., Chuang, U. P., Hersh, E. M. and Mauliquit, G. M. (1981) The palliative role of hepatic arterial infusion and arterial occlusion in colorectal carcinoma metastatic to the liver. Lancet i: $349-350$.

Phillips, T. W., Chander, W. F., Kindt, G. W., Ensminger, W. D., Greenberg, H. S., Seeger, J. F., Doan, K. M. and Gyves, J. W. (1982) A new implantable continuous and bolus intra-carotid drug delivery system for the treatment of malignant gliomas. Neurosurg. 11: 213-218.

Pinedo, H. M. and Chabner, B. A. (1977) Role of drug concentration, duration of exposure and endogeneous metabolites in determining methotrexate cytotoxicity. Cancer Treat. Rep. 61: 709-715.

Ramming, K. P., Sparks, F. C., Ellber, F. R., Holmes, E. C. and Morton, D. L. (1976) Hepatic artery ligation and 5-fluorouracil infusion for metastatic colon carcinoma and primary hepatoma. Am. J. Surg. 132: 236-242.

Rieselbach, R. E., Chiro, G. D., Freireich, E. J. and Ralli, D. P. (1962) Subarachroid distribution of drugs after lumbar injection. New Engl J. Med. 267: 1273-1278.

Rohde, T. D., Blackshear, P. J., Varco, R. L. and Buchwald, H. (1977) One year of heparin anticoagulation in an ambulatory subject using a totally implantable infusion pump. Minn. Med. 60: 722.

Sano, K., Hoshino, T. and NAGaI, M. (1968) Radiosensitization of brain tumor cells with a thymidine analogue (bromouridine). J. Neurosurg. 28: 530-538.

Schade, D. S., Eaton, R. P., Edwards, W. S., Doberneck, R. C., Spencer, W. J., Carlson, G. A., Bair, R. E., Love, J. T., Urenda, R. S. and GaONA, J. I., JR. (1982) A remotely programmable insulin delivery system-successful short-term implantation in man. J. Am. med. Ass. 247: 1846-1854.

SCHINDleR, R., Ramseier, L. and Grieder, A. (1966) Increased sensitivity of mammalian cell cultures to radiomimetric alkylating agents following incorporation of 5-bromodeoxyuridine into cellular DNA. Biochem. Pharmac. 15: 2013-2023.

Schwade, J. G., Myers, C. M. and Sonnenfeld, P. (1981) Bromodeoxyuridine (NSC 38297) pharmacokinetics and clinical results with intravenous administration. Rad. Oncol. biol. Physics 7: 9.

Shapiro, W. R., Young, D. F. and Mehta, B. M. (1975) Methotrexate: Distribution in cerebrospinal fluid after intravenous, ventricular and lumbar injections. New Engl. J. Med. 293: 161-166.

SKIPPER, H. E. and SCHABEL, F. M. (1982) Quantitative and cytokinetic studies in experimental tumor systems. In: Cancer Medicine, pp. 663-685, Holland, J. F. and FrEI, E. III (eds), Lea and Febiger, Philadelphia.

Sonneveld, P., Schwade, J. E., Riccardi, R., Speyer, J. L., Poplack, D. G., Glatstein, E., Collins, J. J., Jenkins, J. and MYeRs, C. E. (1982) Clinical pharmacology of bromodeoxyuridine (NSC 38297) a nonhypoxic radiosensitizer. Proc. Am. Ass. Cancer Res. 23: 488-

Speyer, J. L., Collins, J. M., Dedrick, R. L., Brennan, M. F., Buckpitt, A. R., Londu, H., DeVita, V. T., JR. and MYERS, C. E. (1980) Phase I and pharmacological studies of 5-fluorouracil administered intraperitoneally. Cancer Res. 40: 567-572.

Speyer, J. L., Sugarbaker, P. H., Collins, J. M., Dedrick, R. L., Klecher, R. W., JR. and Myers, C. E. (1981) Portal levels and hepatic clearance of 5 -fluorouracil after intraperitoneal administration in humans. Cancer Res. 41: 1916-1922.

TAYLOR, I., Rowling, J. and WeSt, C. (1979) Adjuvant cytotoxic liver perfusion for colorectal cancer. Br. $J$. Surg. 66: 823-837.

Tseng, M. H., Luch, J., Mittelman, A., Ledesma, E. J. and Berjian, R. A. (1981) Chemotherapy of advanced colorectal cancer with regional arterial mitomycin $\mathrm{C}$ infusion and concomittant measurement of serum drug level. Proc. Am. Ass. Cancer Res. 22: 359.

Warren, B. A. (1979) Tumor blood circulation: Angiogenesis, vascular morphology and blood flow of experimental and human tumors. In: The Vascular Morphology of Tumors, pp. 1-47, Peterson, H. I. (ed.). CRC Press, Inc., Florida.

Watkins, E., JR., Hering, A. C., Luna, R. and Adams, H. D. (1960) The use of intravascular balloon catheters for isolation of the pelvic vascular bed during pump-oxygenator perfusion of cancer chemotherapeutic agents. Surg. Gyn. Obstet. 111: 464468.

Yang, P. J., Thrall, J. H., Ensminger, W. D., Niederhuber, J. E., Gyves, J. W., Tuscan, M., Doan, K. and CozzI, E. (1982) Perfusion scintigraphy (Tc-99m MAA) during surgery for placement of chemotherapy catheter in hepatic artery: concise communication. J. nucl. Med. 23: 1066-1069. 